\title{
TRIBUTAÇÃO E CONCORRÊNCIA: O PARADOXO DAS EMPRESAS PÚBLICAS
}

\author{
COMPETITION AND TAXATION: THE PARADOX OF PUBLIC ENTITIES
}

\begin{abstract}
Kristian Rodrigo Pscheidt
Professor dos cursos de graduação e pós-graduação em Direito pela Universidade Tuiuti do Paraná e da Faculdade CNEC Campo Largo. Doutorando e Mestre em Direito Político e Econômico pela Universidade Presbiteriana Mackenzie (2014), possui L.L.M em Direito de Negócios pela FMU (2014), é especialista em Direito Tributário pelo Centro Universitário Curitiba (2010), possui graduação em Direito pela Pontifícia Universidade Católica do Paraná (2008) e graduação em Jornalismo pela Pontifícia Universidade Católica do Paraná (2004). E-mail: kristianpscheidt@bol.com.br
\end{abstract}

Recebido em: 20/06/2016

Aprovado em: 03/08/2016

Doi: $10.5585 / \mathrm{rdb} . v 15 i 6.376$

RESUMO: O Estado possui, entre suas diversas formas de intervir na economia, a prerrogativa constitucional de atuar ativamente como um agente econômico. Por meio de empresas públicas e sociedades de economia mista, exerce função de mercado visando atender padrões da eficiência econômica e, também, estar alinhada a corolários do bem-estar social. O objetivo deste estudo, por meio de pesquisa bibliográfica, é verificar o paradoxo que surge quando a carga tributária sobre tais entidades mostra-se tão onerosa quanto a incidente sobre a iniciativa privada. E arcar com os tributos tal como uma empresa privada, quando pautada por elementos sociais, o fator concorrencial pode ser prejudicado. A análise deste cenário permite concluir que a falta de produtividade gera perdas que são repassadas aos contribuintes.

Palavras-chave: Tributação; Concorrência; Imunidade recíproca; Incentivos fiscais.

\begin{abstract}
The State has, among its many ways of intervening in the economy, the constitutional prerogative to actively act as an economic agent. Through public entities, exerts function to meet standards of economic efficiency and also be aligned with the corollaries of social welfare. The porpoise of this article is to identify the paradox that arises when the tax burden on these entities is shown as costly as the incident on the private sector. And afford the taxes as a private company, when guided by social elements, the competitive element may be impaired. This scenario means that this bill is passed on to taxpayers.
\end{abstract}

Keywords: Taxation, competition, state immunity, tax incentives.

SUMÁRIO: Introdução; 1. As empresas públicas; 1.1 Recursos e resultados - BNDES; 1.2 Recursos e resultados - Caixa Econômica Federal; 2. A discussão sobre a imunidade recíproca; 3. A carga tributária sobre as Empresas Públicas; 4. O custo dessa política transversa; Considerações finais; Referências. 


\section{INTRODUÇÃO}

O Estado, por autorização constitucional, pode atuar como agente de mercado. Em situações de relevante interesse coletivo e por imperativo de segurança nacional ${ }^{1}$, mostra-se possível a criação de uma empresa estatal ou sociedade de economia mista. Com isso, a entidade criada por Lei passa a atuar diretamente como um agente econômico, seja em regime de participação ou absorção (GRAU, 2008).

Assim é que surgiram no Brasil entidades de grande repercussão no dia a dia dos brasileiros, tais como Caixa Econômica Federal, Correios, Banco do Brasil, Banco Nacional de Desenvolvimento Econômico e Social (BNDES), Petrobras, Nossa Caixa Capitalização, Braspetro Oil Services Company, Breitener Energética, Empresa Brasileira de Hemoderivados e Biotecnologia, entre outras. São quase 150 empresas estatais em âmbito federal ${ }^{2}$, e uma infinidade de entidades vinculadas a Estados membros e Municípios.

"Exige-se uma atuação do Estado no sentido de garantir a correta atuação do mercado, estando há muito tempo ultrapassado o modelo liberal novecentesco da mão invisível do mercado" (SALOMÃO FILHO, 2013, p. 414), devendo pautar-se pela repressão ao abuso do poder econômico que vise à dominação dos mercados, à eliminação da concorrência e ao aumento arbitrário dos lucros.

Essas empresas estatais, quando constituídas, passam a atuar em um regime de livre concorrência com o setor privado. A partir desse momento, passa-se a proteção da instituição concorrência, o que mitiga a possibilidade dessas empresas públicas valer-se de incentivos fiscais ou privilégios outros, como obter prazos processuais em dobro. É a própria redação do artigo $173, \S 2^{\circ}$ da Constituição, que enuncia que "as empresas públicas e as sociedades de economia mista não poderão gozar de privilégios fiscais não extensivos às do setor privado".

O problema surge quando o próprio texto constitucional impõe às entidades públicas que a atuação deve pautar-se pelo aspecto social, e não necessariamente econômico. "A atuação do Estado como agente econômico não é inspirada pela mesma lógica especulativa que estimula os empreendedores privados [...] a produção estatal é qualificada por objetivos tipicamente públicos, que nem sempre priorizam a realização de investimentos em função de sua maior lucratividade" (PINTO JUNIOR, 2010, p. 221).

Hoje, dentre as empresas estatais existentes, possuem grande repercussão a Caixa Econômica Federal (CEF) e o BNDES na medida em que estabelecem em sua origem a necessidade de compatibilizarem-se com os aspectos sociais do País; e é sobre essas duas entidades que o presente artigo centralizará sua análise.

A Lei n. 5.662/1971, seguida pelo Decreto-Lei $\mathrm{n}^{\circ}$ 1.940, de 25 de maio de 1982, promoveram a roupagem atual do Banco Nacional de Desenvolvimento Econômico e Social (BNDES), que possui como escopo ser o "instrumento de execução da política de investimento do Governo Federal e tem por objetivo primordial apoiar programas, projetos, obras e serviços que se relacionem com o desenvolvimento econômico e social do País" ${ }^{3}$.

A Caixa Econômica Federal, regulada pelo Decreto-lei no 759 , de 12 de agosto de 1969, possui como objetivos institucionais "conceder empréstimos e financiamentos de natureza assistencial, cooperando com as entidades de direito público e privado na solução dos problemas sociais e econômicos" (artigo 20, "b") e "operar no setor habitacional, como sociedade de crédito

\footnotetext{
${ }^{1}$ De acordo com o artigo 173 da Constituição da República. "Art. 173. Ressalvados os casos previstos nesta Constituição, a exploração direta de atividade econômica pelo Estado só será permitida quando necessária aos imperativos da segurança nacional ou a relevante interesse coletivo, conforme definidos em lei."

${ }^{2}$ BRASIL. Ministério do Planejamento no sitio eletrônico http://www.planejamento.gov.br/assuntos/empresasestatais/empresas-estatais-federais.

${ }^{3}$ Conforme artigo $3^{\circ}$ do Estatuto atual - Decreto ${ }^{\circ} 4.418$, de 11 de outubro de 2002.

Revista de Direito Brasileira | São Paulo, SP | v. 15 | n. 6 | p. 295 - 310 | set./dez. 2016
} 
imobiliário e principal agente do Banco Nacional de Habitação, com o objetivo de facilitar e promover a aquisição de sua casa própria, especialmente pelas classes de menor renda da população" (artigo 20, “c”).

Porém, muito embora tenham seu alicerce construído sobre uma justificativa social, em termos tributários, não gozam de nenhum benefício. A imunidade recíproca prevista no artigo 150, VI, "a" da Constituição, sempre suscitada nessa temática, vem sendo reiteradamente rechaçada pelo Supremo Tribunal Federal ${ }^{4}$ sob os seguintes argumentos:

a) a imunidade tributária recíproca se aplica apenas à propriedade, bens e serviços utilizados na satisfação dos objetivos institucionais imanentes do ente federado; b) atividades de exploração econômica, destinadas primordialmente a aumentar o patrimônio do Estado ou de particulares, devem ser submetidas à tributação, por apresentarem-se como manifestações de riqueza e deixarem a salvo a autonomia política; e c) a desoneração não deve ter como efeito colateral relevante a quebra dos princípios da livre concorrência e do livre exercício de atividade profissional ou econômica lícita. (STF. ACO 1460 AgR, Relator(a): Min. DIAS TOFFOLI, Tribunal Pleno, julgado em 07/10/2015, DJe-249 DIVULG 10-12-2015 PUBLIC 11-12-2015)

Com tais elementos é que surge o problema fundamental deste artigo, que é analisar como as entidades públicas criadas sob um escopo social são obrigadas a direcionar seus recursos para projetos sociais, reduzindo a possibilidade de maximizar os lucros frente a livre competição com os demais agentes de mercado, ao mesmo tempo em que sofrem a mesma carga tributária de qualquer outro agente privado. Pretende-se verificar o resultado desse aparente paradoxo, descobrindo-se quem está arcando com esse déficit competitivo.

O objetivo que se pretende ao escrever sobre o assunto é conceder um olhar crítico sobre a situação envolvendo estas empresas, em especial para que o leitor possa ater-se a falta de planejamento do Poder Público ao definir suas posições estratégicas. É certo que se vive em um Estado Fiscal, "precipuamente dos ingressos tributários, reduzindo, pela privatização de suas empresas e pela desregulamentação do social, o aporte de receitas patrimoniais e parafiscais" (TORRES, 2009, p. 9). A importância da arrecadação é essencial, mas ela deve ser efetivada mesmo naquelas entidades que possuem em seu objetivo institucional promover programas de desenvolvimento socioeconômicos? "É importante discutir os efeitos distributivos das atividades [do BNDES], mas é fundamental perguntar se essa enorme intervenção estatal no mercado de crédito contribui para a nação gerar mais riqueza" (GUIMARÃES, 2015, p. 56).

Sobre tais elementos este estudo será realizado eminentemente por pesquisa bibliográfica e jurisprudencial, que se somam a dados estatísticos e econômicos divulgados pelas próprias entidades mencionadas neste estudo. Não se trata de analisar somente o alcance da imunidade recíproca prevista no artigo 150, VI, "a" da Constituição, tão discutida nos tempos atuais, mas sim de analisar o impacto desse paradoxo entre tributação, competição e o uso de recursos públicos de forma a sustentar essa relação redistributiva.

\footnotetext{
${ }^{4}$ Precedentes: RE no 253.472/SP, Tribunal Pleno, Relator para o acórdão o Ministro Joaquim Barbosa, DJe de 1\%/2/11 e e ACO 2243/DF, decisão monocrática, Relator Min. Dias Toffoli, DJe de 25/10/13. Há que ressaltar que a discussão ainda é tema de repercussão geral naquele tribunal em dois recursos: a) ARE 643686 RG, Relator(a): Min. DIAS TOFFOLI, julgado em 11/04/2013, ACÓRDÃO ELETRÔNICO DJe-083 DIVULG 03-05-2013 PUBLIC 0605-2013; e b) ARE 638315 RG, Relator(a): Min. MINISTRO PRESIDENTE, julgado em 09/06/2011, REPERCUSSÃO GERAL - MÉRITO DJe-167 DIVULG 30-08-2011 PUBLIC 31-08-2011 EMENT VOL-02577-02 PP-00183. O julgamento de tais recursos poderão alterar os parâmetros já fixados pelo próprio STF.
}

Revista de Direito Brasileira | São Paulo, SP | v. 15 | n. 6 | p. 295 - 310 | set./dez. 2016 


\section{AS EMPRESAS PÚBLICAS}

Empresas públicas são caracterizadas, a rigor do artigo $5^{\circ}$ do Decreto-lei n. 200/1967, como sendo a entidade dotada de personalidade jurídica de direito privado, com patrimônio próprio e capital exclusivo da União, criado por lei para a exploração de atividade econômica que o Governo seja levado a exercer por força de contingência ou de conveniência administrativa podendo revestir-se de qualquer das formas admitidas em direito. São criadas, mantidas e regidas pelo Poder Público. Nelas, o controle acionário que o Estado detém é integral, ou seja, o Ente político é detentor de $100 \%$ das ações da sociedade.

Surgem no desenvolvimento de função de integração capitalista - na medida em que sua atuação está vocacionada à preservação dos mercados - justificando-se a sua existência, fundamentalmente, pelo atendimento imediato, cumulativo ou não, dos seguintes objetivos: "supressão de incapacidade ou falta de interesse econômico momentâneo do setor privado na exploração da atividade; supressão da insuficiência da oferta; coibição de situação de monopólio de fato; implementação da função social da propriedade e promoção do pleno emprego" (GRAU, 1984, p. 52).

A empresa estatal no mercado "contribui para o fortalecimento da concorrência, com consideráveis ganhos para o conjunto da sociedade" afirma Mario Engler Pinto Junior (2010, p. 259), conquanto atuam em serviços não aparentemente lucrativos para a iniciativa privadas, corrigindo falhas de mercado e práticas abusivas dos demais players. O papel da empresa estatal, desde que tenha poder de mercado suficiente, é "ser o planejador e direcionador de desenvolvimento setorial" (SALOMÃO FILHO, 2002, p. 60), permitindo-se assim melhor conhecimento da realidade e, eventualmente, a mudança de rumo do planejamento.

Exercem um papel central no Estado brasileiro, liberal capitalista em suas regras mas social interventor em suas atitudes. Além de um arcabouço legislativo complexo e exauriente, pauta-se o Estado Democrático de Direito pela atuação direta e elogiada na economia, por meio de suas estatais. Neste sentido, para compreensão do presente estudo, em um primeiro momento, é imperativo conhecer, ainda que de modo superficial, as características essenciais de cada uma das empresas objeto de análise.

\subsection{Recursos e Resultados - BNDES}

O BNDES é considerado como um modelo internacional de estratégia governamental voltado ao financiamento de tecnologias e investimento em $\mathrm{P} \& \mathrm{D}^{5}$. "Atua no negócio de emprestar fundos do governo a indústrias ou a empresas específicas para executar projetos de longa maturação ou de alto impacto social cujo financiamento seria pouco atraente para bancos comerciais" (MUSACCHIO, LAZZARINI, 2014, p. 294).

Foi instituído pela Lei n. 5.662/1971, seguida pelo Decreto-Lei n ${ }^{\circ} 1.940$, de 25 de maio de 1982, que promoveram a roupagem atual do BNDES, que possui como escopo ser o "instrumento de execução da política de investimento do Governo Federal e tem por objetivo primordial apoiar programas, projetos, obras e serviços que se relacionem com o desenvolvimento econômico e social do País", conforme artigo $3^{\circ}$ do Estatuto atual - Decreto $\mathrm{n}^{\circ}$ 4.418, de 11 de outubro de 2002.

Compõem-se ainda de duas subsidiárias integrais: a Finame e a BNDESPAR. Juntas, as três empresas compreendem o chamado Sistema BNDES. A Agência Especial de Financiamento Industrial (Finame) foi criada em 1966, para gerir o então existente Fundo de Financiamento para

\footnotetext{
${ }^{5}$ Conforme Mariana Mazzucato (2014, p. 254), o BNDES é "um bom exemplo de banco de desenvolvimento econômico brasileiro, que investe ativamente em inovação tanto em tecnologia limpa quanto em biotecnologia"

Revista de Direito Brasileira | São Paulo, SP | v. 15 | n. 6 | p. 295 - 310 | set./dez. 2016
} 
Aquisição de Máquinas e Equipamentos Novos. Suas atividades são desenvolvidas sob a responsabilidade e com a colaboração do BNDES. Já o BNDESPAR é uma sociedade por ações. O seu capital social subscrito está representado por uma única ação, nominativa, sem valor nominal, de propriedade do BNDES, tendo como um de seus objetivos realizar operações visando à capitalização de empreendimentos controlados por grupos privados, observados os planos e políticas do BNDES.

Como o próprio BNDES enuncia, das fontes de recursos que compõem a estrutura de capital, destacam-se as governamentais, como FAT, o PIS-PASEP e o Tesouro Nacional, que representam parcela significativa de sua estrutura de financiamento, somados aos recursos do Fundo de Marinha Mercante e do FI-FGTS, também completam estas fontes, compondo o seguinte gráfico:

\section{Fontes de recursos do BNDES}

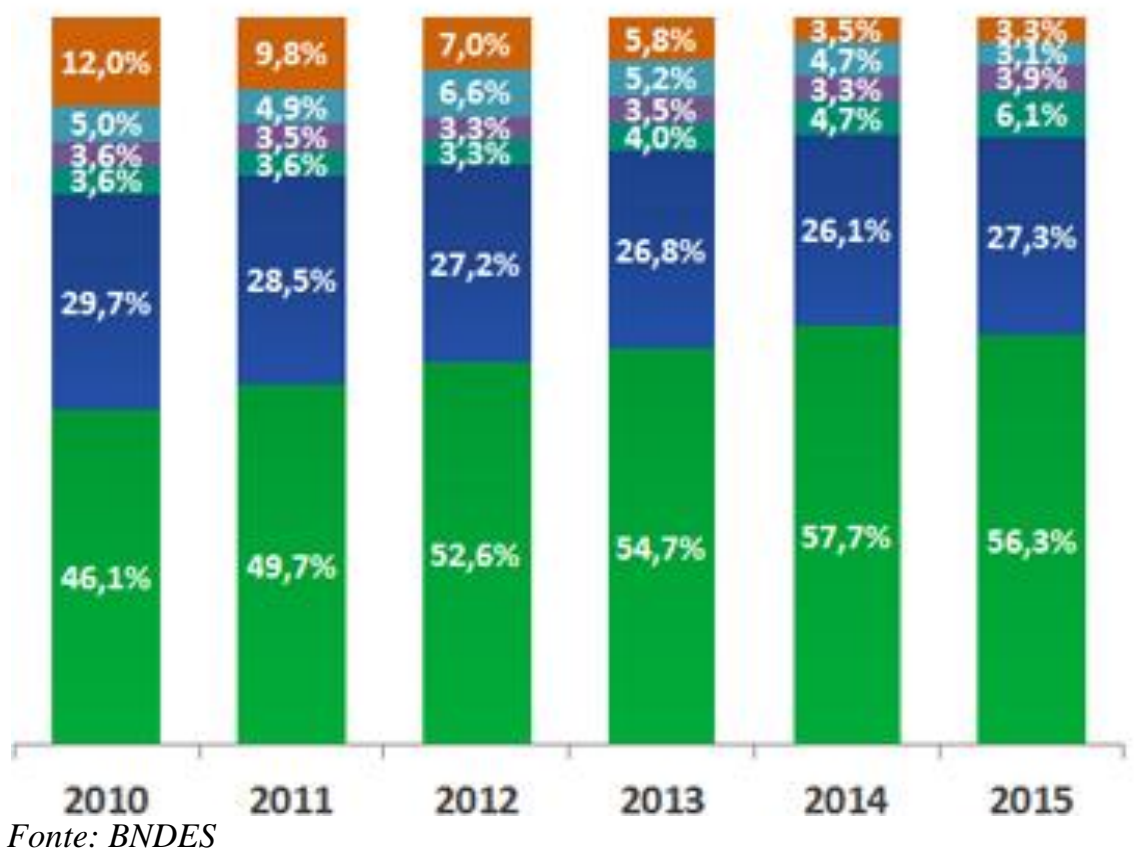

Patrimônio líquido

Outras obrigações

- Outras fontes governamentais

Captações externas

FAT/PIS-PASEP

Tesouro Nacional

Essas fontes públicas de investimento resultam no saldo das obrigações do BNDES com o Tesouro Nacional em 31 de dezembro de 2015 é de R\$523,7 bilhões ${ }^{6}$. O BNDES é responsável pela aplicação da maior parte dos recursos do Fundo, na proporção de aproximadamente $90 \%$ do total, cabendo à Caixa Econômica Federal e ao Banco do Brasil a aplicação da parcela complementar.

Conforme dispõe a Lei Complementar n. 19, de 25 de junho de 1974, regulamentada pelo Decreto no 74.333, de 30 de junho de 1974, os recursos do Programa de Integração Social PIS e do Programa de Formação do Patrimônio do Servidor Público - PASEP passaram a ser aplicados, a partir de 1974, pelo Banco Nacional de Desenvolvimento Econômico e Social, de acordo com programas especiais de investimento elaborados segundo diretrizes aprovadas pelo Presidente da República. Esta atribuição continuou prevalecendo após a instituição, pela Lei Complementar n. 26, de 11 de setembro de 1975, do Fundo PIS-PASEP, resultante da unificação dos dois Fundos originais.

\footnotetext{
${ }^{6}$ De acordo com o próprio BNDES no site:

http://www.bndes.gov.br/SiteBNDES/bndes/bndes_pt/Institucional/O_BNDES/Fontes_de_Recursos/. Acesso em: 20 abr. 2016.
}

Revista de Direito Brasileira | São Paulo, SP | v. 15 | n. 6 | p. 295 - 310 | set./dez. 2016 
O Banco Nacional de Desenvolvimento Econômico e Social (BNDES) desembolsou R\$ 136 bilhões para projetos de investimento em 2015. O setor de Infraestrutura foi o que registrou maior participação, com $\mathrm{R} \$ 54,9$ bilhões, ou 40,4\% do total, seguido dos setores de Indústria para o qual o BNDES desembolsou R \$ 36,9 bilhões $(27,1 \%)-$, Comércio e Serviços (R \$ 30,4 bilhões, ou 22,4\%) e Agropecuária (R\$13,7 bi, ou 10,1\%).

De acordo com o Boletim de Desempenho Setorial do $\mathrm{BNDES}^{7}$, na comparação 2014, houve recuo de $28 \%$ nos desembolsos. As aprovações atingiram $\mathrm{R} \$ 109,5$ bilhões, e as consultas, $\mathrm{R} \$ 124,6$ bilhões. Os dois indicadores tiveram recuo de $47 \%$ em relação a 2014. O desempenho acompanha a desaceleração da demanda por novos investimentos e foi influenciado pela política de ajuste fiscal implementada pelo Governo Federal.

No entanto, de acordo com dados revelados pelo próprio $\mathrm{BNDES}^{8}$, registrou lucro líquido de $\mathrm{R} \$ 6,639$ bilhões nos nove primeiros meses de 2015. O principal fator positivo foi o aumento do resultado de intermediação financeira, que alcançou R \$ 14,515 bilhões, valor 52,9\% superior ao registrado em igual período de 2014. Outro indicador positivo foi a inexpressiva inadimplência do BNDES, de 0,02\%, bem abaixo da média do Sistema Financeiro Nacional (SFN), de 3,1\%, no período e que reflete a alta qualidade da carteira de crédito do Banco.

\subsection{Recursos e Resultados - Caixa Econômica Federal}

A Caixa Econômica Federal, regulada pelo Decreto-lei no 759, de 12 de agosto de 1969, possui como objetivos institucionais "conceder empréstimos e financiamentos de natureza assistencial, cooperando com as entidades de direito público e privado na solução dos problemas sociais e econômicos" (artigo 20, "b") e "operar no setor habitacional, como sociedade de crédito imobiliário e principal agente do Banco Nacional de Habitação, com o objetivo de facilitar e promover a aquisição de sua casa própria, especialmente pelas classes de menor renda da população" (artigo 20, "c").

É o agente responsável pelo Fundo de Garantia do Tempo de Serviço (FGTS), pelo Programa de Integração Social (PIS) e pelo Seguro-Desemprego, institutos presentes na vida do trabalhador formal. Atua ainda como gestor do Bolsa Família, FIES e Programa Minha Casa Minha Vida.

Como evidencia em seu sítio eletrônico9", "prioriza setores como habitação, saneamento básico, infraestrutura e prestação de serviços, contribuindo significativamente para melhorar a vida das pessoas, principalmente as de baixa renda". Com tais objetivos institucionais, apresenta as seguintes fontes de recursos ${ }^{10}$ :

a) Crédito imobiliário e política para o setor habitacional: participa das discussões sobre a proposta da nova Política Nacional da Habitação, conduzida pelo Ministério das Cidades;

b) Fundo de Garantia por Tempo de Serviço - FGTS: na qualidade de Agente Operador do FGTS administra recursos de mais de R\$ 153 bilhões e um

\footnotetext{
${ }^{7}$ BNDES. Desempenho setorial 2015. Disponível em:

<http://www.bndes.gov.br/SiteBNDES/export/sites/default/bndes_pt/Galerias/Arquivos/empresa/estatisticas/Bol_De sempenho_e_Setorial.pdf > Acesso em: 20 abr. 2016.

8 BNDES. Lucro do BNDES até setembro foi de $R \$ \quad 6,6$ bilhões. Disponível em: <http://www.bndes.gov.br/SiteBNDES/bndes/bndes_pt/Institucional/Sala_de_Imprensa/Noticias/2015/Institucional/ 20151113_lucro.html> Acesso em: 20 abr. 2016.

${ }^{9}$ Disponível em: <http://www.caixa.gov.br/sobre-a-caixa/apresentacao/Paginas/default.aspx >

${ }^{10}$ De acordo com http://www1.caixa.gov.br/mpraticas/sobre_caixa.asp?idioma=p
} Revista de Direito Brasileira | São Paulo, SP | v. 15 | n. 6 | p. 295 - 310 | set./dez. 2016 
cadastro de 447 milhões de contas vinculadas dos trabalhadores e 2 milhões de empresas que contribuem mensalmente para o Fundo;

c) Fundo de Amparo ao Trabalhador - FAT: opera atualmente R \$ 2 bilhões nos seguintes Programas: PROGER Urbano (R \$ 980 milhões), FAT Habitação (R\$ 870 milhões), FAT Eletrodomésticos (R\$ 87 milhões). Ademais, o CODEFAT já aprovou as Resoluções para os Programas FAT Revitalização (R\$ 200 milhões) e FAT Vila Panamericana (R \$ 350 milhões);

d) Caderneta de Poupança: possui a liderança na captação de depósitos de poupança, detendo $31 \%$ do mercado total, com 24 milhões de poupadores e saldo em carteira superior a $\mathrm{R} \$ 44$ bilhões;

e) Sistema Financeiro Imobiliário - SFI: a consolidação do Sistema Financeiro Imobiliário - SFI é a principal solução para a ampliação do crédito imobiliário, mediante o amplo desenvolvimento do mercado secundário de recebíveis imobiliários, conferindo maior atratividade aos CRI (Certificados de Recebíveis Imobiliários) facilitando a sua colocação primária;

f) Viabilidade da Parceria Público-Privada: estimula a parceria dos setores público e privado no investimento em projetos estruturados, por intermédio da securitização de recebíveis: por meio de Sociedades de Propósito Específico SPE; locação de ativos, créditos imobiliários de ativos, créditos de contratos de fornecimento; via constituição de Fundos de Investimento em Direitos Creditórios - FIDC;

g) Fundo de Investimento em Direitos Creditórios - FIDC: instrumento para otimizar alocação de recursos, combina os modernos mecanismos de securitização e fundo de investimento para estimular o investimento em projetos habitacionais e de infraestrutura urbana.

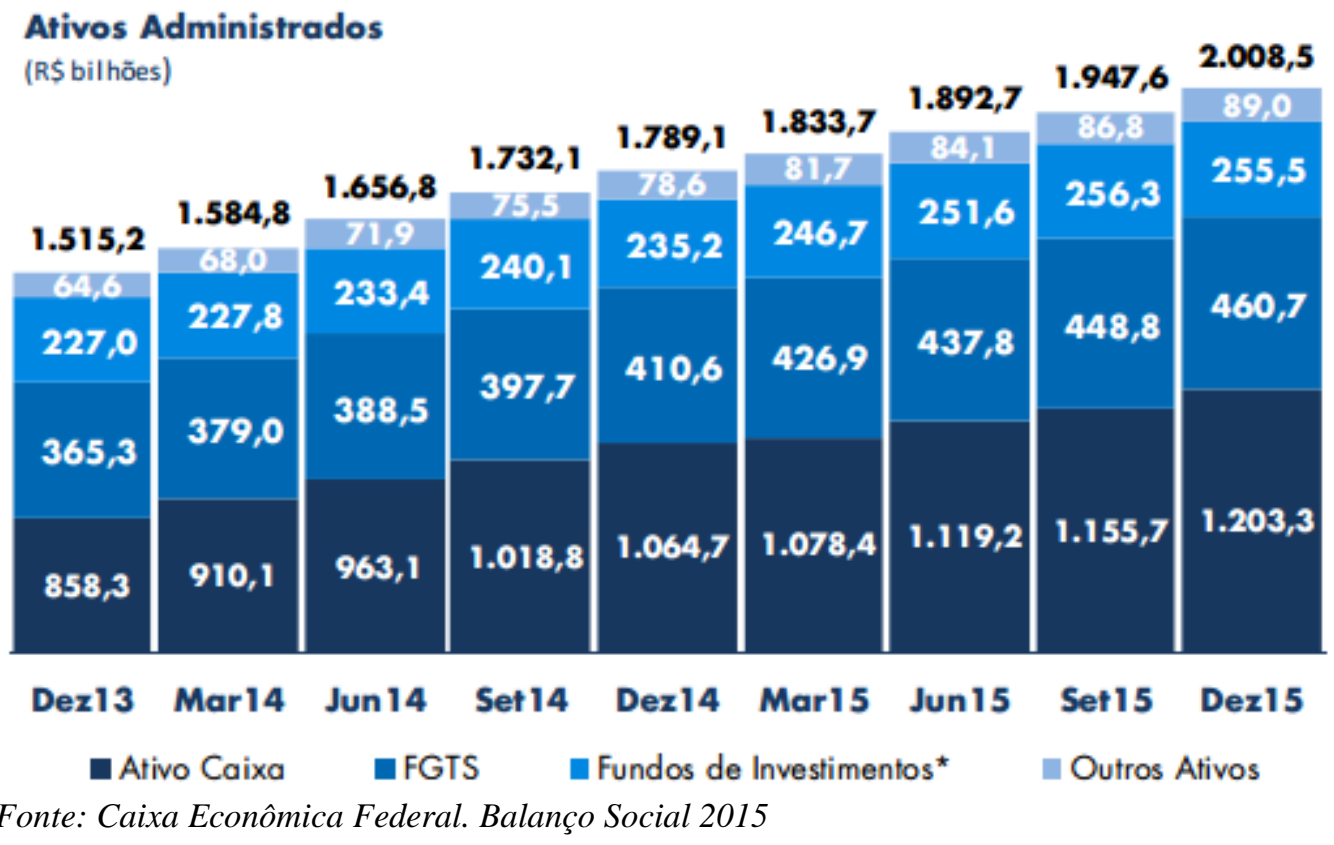

Com tais fontes de recursos e modelo de atuação, registrou lucro líquido de $\mathrm{R} \$ 7,2$ bilhões em 2015 , valor $0,9 \%$ superior ao obtido no ano de $2014^{11}$. Os principais destaques do resultado do ano passado foram as receitas originadas pelo relacionamento com clientes nas

\footnotetext{
${ }^{11}$ Caixa anuncia lucro de $\mathrm{R} \$ 7,2$ bilhões e medidas para crédito imobiliário. Portal G1. Publicado em 08/03/2016. Disponível em: <http://g1.globo.com/economia/negocios/noticia/2016/03/lucro-da-caixa-economica-sobe-para-r-72bilhoes-em-2015.html> Acesso em: 20 abr. 2016.
}

Revista de Direito Brasileira | São Paulo, SP | v. 15 | n. 6 | p. 295 - 310 | set./dez. 2016 
contas correntes e cestas de serviços, que cresceram 30,7\%, pelos cartões de crédito em $12 \%$ e pelos convênios e cobrança em 10,1\%.

A carteira de crédito avançou 11,9\% em 12 meses e alcançou saldo de R \$ 679,5 bilhões, representando $20,9 \%$ do mercado. O crédito habitacional continuou a ser o principal destaque do crédito, com evolução de $13 \%$ no ano e saldo de $\mathrm{R} \$ 384,2$ bilhões. O valor representa $67,2 \%$ do mercado do país.

Pelos números apresentados pelo BNDES e CEF em 2015, a questão inerente a carga tributária parece não ser significativa frente aos avultantes lucros obtidos por essas instituições. Porém, para se obter com melhor crítica uma análise desses números, necessário realizar uma breve comparação com os demais bancos privados.

Em 2015, o maior banco brasileiro, Itaú-Unibanco divulgou um lucro líquido de $\mathrm{R} \$$ 23,35 bilhões, enquanto que o segundo colocado, Banco Bradesco, totalizou um lucro de R\$ 17,19 bilhões. O Banco do Brasil figura em terceiro, com R\$ 14,4 bilhões de lucro, sendo que somente em $4^{\circ}$ é que se situa a $\mathrm{CEF}$, de acordo com compilação realizada pela Federação dos Bancários do Paraná.

Surge aí uma pergunta elementar: o que justifica a CEF e o BNDES, ainda que se utilizem de recursos públicos e uma estrutura legal que os favorece, não estarem situados nas primeiras posições? A questão tributária poderia ser a resposta?

\section{A DISCUSSÃO SOBRE A IMUNIDADE RECÍPROCA}

Importantes doutrinadores centram a discussão do tema unicamente sobre o alcance da imunidade recíproca prevista no artigo 150, VI, "a" da Constituição. O texto constitucional expressa que é vedado à União, aos Estados, ao Distrito Federal e aos Municípios instituir impostos sobre "patrimônio, renda ou serviços, uns dos outros". Sendo a imunidade ainda extensiva às autarquias e às fundações instituídas e mantidas pelo Poder Público, no que se refere ao patrimônio, à renda e aos serviços, vinculados a suas finalidades essenciais ou às delas decorrentes.

É a tradução do pacto federativo, que visa afastar interferências e garantir a independência aos Estados membros e Municípios. A imunidade recíproca deve ser entendida como cláusula pétrea (art. $60, \S 4^{\circ}$ ) na Constituição Federal, por ser intimamente ligada a manutenção do sistema federativo e "objetiva a proteção do federalismo" (AMARO, 2014, p. 178), sendo o que se imuniza é o patrimônio, a renda e os serviços dos entes da federação, o que não impede a incidência de impostos indiretos.

Por isso que, acaso for constatada a preponderância do serviço público exercido pela empresa pública, Humberto Ávila (2004, p. 215) é enfático ao enunciar que "a imunidade recíproca alcança todos os serviços públicos, independentemente da forma jurídica utilizada pela entidade que o presta". Roque Antonio Carraza (2004, p. 49-50) reforça afirmando que as empresas públicas e sociedades de economia mista que prestam serviço público "acabam fazendo as vezes das autarquias, [...] desse modo não podem ter embaraçada ou anulada sua ação pública, por meio de impostos".

Sendo assim, como afirma Celso Antonio Bandeira de Mello (2007), as empresas públicas e as sociedades de economia mista terão a imunidade quando estarem atuando frente aos objetivos do Estado, devendo a análise ir além do próprio nome iuris que carregam.

Nesse caso, mesmo constituída como pessoa jurídica de direito privado para a exploração da atividade econômica, não pode ser automaticamente tomada como determinante para a definição do seu regime jurídico, em especial porque a Constituição Federal, art. 173, $\S 1^{\circ}$ impõe a aplicação do regime de direito privado, o faz exclusivamente e expressamente às 
empresas públicas e sociedades de economia mista que explorem atividade econômica, nada referindo sobre aquelas que prestam serviços públicos (WUSTER, 2013).

Esse é o critério que o Supremo Tribunal Federal tem adotado ao decidir, de forma reiterada, que a Empresa Brasileira de Correios e Telégrafos - ECT faz jus a imunidade tributária recíproca, pois atua "como entidade delegatária dos serviços públicos a que se refere o art. 21, inciso X, da Lei Fundamental"12. Não é tributado porque exerce essencialmente serviços públicos.

Porém, essa análise não é suficiente ao presente estudo, porque empresas como a Caixa Econômica Federal e o BNDES exercem nitidamente atividade econômica; mas também submetem-se compulsoriamente, por força de lei, aos corolários de uma justiça social redistributiva. De tal forma, na ótica do STF, porquanto realiza "atividade de exploração econômica, destinadas primordialmente a aumentar o patrimônio do Estado ou de particulares, devem ser submetidas à tributação", sob pena de ofender a livre concorrência ${ }^{13}$.

Ocorre que no momento em que a empresa pública é onerada duplamente (com objetivos sociais e a carga tributária), sofre automaticamente uma desvantagem competitiva com qualquer entidade do mercado. Como enfatiza Bernardo Guimarães, no momento em que os empréstimos realizados pelo BNDES, por exemplo, não seguem a taxa de juros Selic mas sim o índice Taxa de Juros a Longo Prazo (TJLP), "suas operações custam caro aos bolsos do cidadãos que são, em última instância, os que sustentam o banco via impostos" (GUIMARÃES, 2015, p. 44). E sobre tais valores, ainda, a tributação ocorre de forma integral, tendo o contribuinte que arcar duplamente com os recursos da entidade.

Porém, antes de avançar nesse paradoxo, e para melhor entender o funcionamento de r. entidades, importante realizar um breve esforço de identificação de cada uma delas (BNDES e $\mathrm{CEF}$ ), em especial no tocante à carga tributária incidente.

\section{A CARGA TRIBUTÁRIA SOBRE AS EMPRESAS PÚBLICAS}

As pessoas jurídicas de direito privado, no Brasil, sofrem com uma carga tributária considerada por muitos como desleal, abusiva e confiscatória. Trata-se de um índice obtido mediante a comparação entre a totalidade da riqueza produzida no país (PIB) e o valor arrecadado a título de tributos. "A carga tributária subiu de 27,26\% no ano de 1995 para 35,80\% em 2008. Com a crise econômica veio baixar em 2009 para 33,08\% e, em 2012, totalizou 35,85\% do PIB" (BUFFON, MATOS, 2015, p. 208).

Nesse sentido ver interessante raciocínio realizado por Eduardo Ferreira Marcial Jardim ao estudar a carga tributária nacional, porquanto parte do PIB se constitui em receitas que se sustentam em isenções e benefícios fiscais, "portanto, mesmo em relação ao PIB composto por receitas produzidas por incentivos não tributados parcialmente, seu percentual corresponderia a $54,83 \%$ e não a 35,41\%, consoante quer o número oficial" (JARDIM, 2015, p. 160-161).

A despeito da ferocidade do sistema tributário nacional, é possível consolidar a carga tributária de uma empresa no seguinte quadro de incidências/alíquotas, considerando-se possuir como objeto a prestação de serviços de intermediação financeira (que é o caso do BNDES e CEF) no Município de São Paulo/SP:

\section{Carga tributária incidente sobre instituição financeira privada/pública}

\footnotetext{
${ }^{12}$ ACO 2654 AgR, Relator(a): Min. CELSO DE MELLO, Tribunal Pleno, julgado em 03/03/2016, ACÓRDÃO ELETRÔNICO DJe-053 DIVULG 21-03-2016 PUBLIC 22-03-2016.

${ }^{13}$ STF. ACO 1460 AgR, Relator(a): Min. DIAS TOFFOLI, Tribunal Pleno, julgado em 07/10/2015, DJe-249 DIVULG 10-12-2015 PUBLIC 11-12-2015

Revista de Direito Brasileira | São Paulo, SP | v. 15 | n. 6 | p. 295 - 310 | set./dez. 2016
} 


\begin{tabular}{|c|c|c|}
\hline Tributo & Critério material ou base & Alíquota \\
\hline Imposto de Renda & Obtenção de renda & $15 \%$ \\
\hline ISS & Prestação de serviços & $6 \%$ \\
\hline CSLL & Lucro Líquido & $20 \%$ \\
\hline PIS & Receitas & $1,65 \%$ \\
\hline Cofins & Receitas & $7,6 \%$ \\
\hline Contribuição previdenciária & Folha de pagamento & $20 \%$ \\
\hline Adicional contribuição prev. & Folha de pagamento & $2,5 \%$ \\
\hline Adic. Apos. Especial & Folha de pagamento & $1 \%$ até $3 \%$ \\
\hline Contribuição de terceiros & Folha de pagamento & $2,7 \%$ \\
\hline Fundeb & Salário educação & $2,5 \%$ \\
\hline FGTS* & Folha de pagamento & $8 \%$ \\
\hline
\end{tabular}

*Muito embora o FGTS não se trate de tributo, onera as operações por serem recolhidas pela pessoa jurídica. Fonte: elaborado pelo autor de acordo com a legislação nacional, considerando-se apuração pelo Lucro Real.

As empresas públicas, por sua vez, sofrem uma carga tributária de fardo idêntico. Por disposição expressa do artigo 146, $\S 4^{\circ}$ do Regulamento do Imposto de Renda (Decreto $\mathrm{n}$. 3.000/1999), "as empresas públicas e as sociedades de economia mista, bem como suas subsidiárias, são contribuintes nas mesmas condições das demais pessoas jurídicas".

De igual forma, com relação a contribuição social sobre o lucro das pessoas jurídicas (CSLL), preconiza o artigo $4^{\circ}$ da Lei n. 7.689, de 15 de dezembro de 1988, que "são contribuintes as pessoas jurídicas domiciliadas no País e as que lhes são equiparadas pela legislação tributária". Por isso, estão sujeitas ao pagamento da CSLL as pessoas jurídicas e as pessoas físicas a elas equiparadas, domiciliadas no País. A alíquota, no caso das pessoas jurídicas consideradas instituições financeiras, de seguros privados e de capitalização, por força da Lei ${ }^{\circ}{ }^{13}$.169, de 6 de outubro de 2015, passou a ser de $20 \%$ (vinte por cento).

Com referência ao Imposto sobre Serviços (ISS), conforme tabela anexa a Lei do Município de São Paulo $\mathrm{n}^{\circ}$ 13.476, de 30 de dezembro de 2002, a alíquota para prestação de serviços por instituições financeiras será de $6 \%$. Aliás, a autorização advém da lista de serviços anexa à Lei Complementar $n^{\circ} 116$, de 31 de julho de 2003, em específico no item 15 que relaciona os serviços relacionados ao setor bancário ou financeiro, inclusive aqueles prestados por instituições financeiras autorizadas a funcionar pela União ou por quem de direito.

As instituições financeiras privadas se submetem a Contribuição aos Programas de Integração Social (PIS) na forma indicada pela Lei n. 10.637, de 30 de dezembro de 2002, não havendo exceção para as empresas estatais. A alíquota, a rigor do artigo $2^{\circ}$, é de $1,65 \%$ (um inteiro e sessenta e cinco centésimos por cento).

Com referência a Contribuição para o Financiamento da Seguridade Social - Cofins, instituída de forma não cumulativa pela Lei n. 10.833, de 29 de dezembro de 2003, também não excepciona a incidência, sujeitando-se as entidades estatais ao pagamento de 7,6\% (sete vírgula seis por cento) incidentes sobre o total das receitas auferidas no mês. 
A contribuição previdenciária, cota patronal, nos termos do artigo 22 da Lei n. 8.212/1991, é devida pelas instituições financeiras o montante de $20 \%$ (vinte por cento) sobre o total das remunerações pagas, devidas ou creditadas a qualquer título aos funcionários, acrescido do montante de $1 \%$ a $3 \%$ para fins de subsidiar a aposentadoria especial. Além disso, especificamente para os bancos comerciais, bancos de investimentos, bancos de desenvolvimento, caixas econômicas, sociedades de crédito, financiamento e investimento, entre outros, nos termos do $\S 1^{\circ}$ do artigo 22 da Lei n. 8.212/1991, ainda é devida a contribuição adicional de $2,5 \%$ (dois vírgula cinco por cento) sobre a base de cálculo da contribuição. Empresas públicas não possuem qualquer regulamento diferenciado.

As contribuições do art. 149 da Constituição da República, também conhecida como Contribuição ao Sistema $\mathrm{S}$ ou contribuições devidas a terceiros, na forma do artigo $3^{\circ}$ da Lei $\mathrm{n}^{\circ}$ 11.457, de 16 de março de 2007, para os bancos comerciais, aplica-se a o código FPAS n. 736, o que resulta uma alíquota de $2,7 \%$ (dois vírgula sete por cento). As empresas públicas, igualmente, devem contribuir tal como a iniciativa privada.

A contribuição social do salário-educação, que está prevista no artigo $212, \S 5^{\circ}$, da Constituição Federal, regulamentada pelas leis n's 9.424/96, 9.766/98, Decreto $n^{\circ}$ 6003/2006 e Lei $\mathrm{n}^{\mathrm{o}} 11.457 / 2007$. É calculada com base na alíquota de 2,5\% sobre o valor total das remunerações pagas ou creditadas pelas empresas, a qualquer título, aos segurados empregados.

Por fim, com relação ao Fundo de Garantia do Tempo de Serviço - FGTS, hoje regido pela Lei $\mathrm{n}^{\circ}$ 8.036, de 11 de maio de 1990, muito embora não se trate de tributo, exige que as empresas públicas, a rigor da disposição do artigo 15, depositem, até o dia 7 (sete) de cada mês, em conta bancária vinculada, a importância correspondente a 8 (oito) por cento da remuneração paga ou devida, no mês anterior, a cada trabalhador.

Há que se destacar, ainda, que a Instrução Normativa RFB no 1.234, de 2012, ainda determinou que os órgãos da administração federal direta, as autarquias, as fundações federais, as empresas públicas, as sociedades de economia mista e as demais entidades em que a União, direta ou indiretamente detenha a maioria do capital social sujeito a voto, e que recebam recursos do Tesouro Nacional e estejam obrigadas a registrar sua execução orçamentária e financeira no Sistema Integrado de Administração Financeira do Governo Federal (Siafi), deverão efetuar a retenção do IRRF, da Contribuição Social sobre o Lucro Líquido (CSLL), da Contribuição para o Programa de Integração Social (PIS) e da Contribuição para o Financiamento da Seguridade Social (Cofins), nos pagamentos efetuados pelo fornecimento de bens e pela prestação de serviços em geral, inclusive obras, a tais pessoas jurídicas. E tais retenções sequer poderão ser apropriadas pelos Municípios, a rigor do disposto no artigo 158, I, da Constituição.

De tal forma, verifica-se que na questão tributária nenhum benefício é concedido para as empresas públicas, em específico a CEF e o BNDES. A competição com os demais agentes ocorre de forma igualitária, o que é um viés negativo se considerados todos os demais limites que possuem essas instituições ao serem regrados por normas de Direito Público. Para não fugir do escopo do presente artigo, basta mencionar que a natureza pública exige destas empresas a contratação de pessoal mediante concurso de pessoas, transparência nas suas atividades e, ainda, contratação de obras e serviços obedecendo-se a Lei 8.666/1993. São os princípios da Administração Pública, amplamente previstos no artigo 37 da Constituição da República.

Neste curto cenário é possível identificar desde já uma desvantagem competitiva com o mercado privado das instituições financeiras. Pautados por limites da Administração Pública, as empresas estatais devem realizar um processo moroso e custoso de suas atividades rotineiras, devendo arcar com uma carga tributária de igual fardo. Isso sem mencionar os aspectos sociais que dirigem os investimentos, tal como se referencia abaixo. 


\section{O CUSTO DESSA POLÍTICA TRANSVERSA}

As análises até agora realizadas indicam que o fardo tributário sobre as empresas estatais são idênticas àquelas sofridas pela iniciativa privada, porém, de outro lado, o BNDES e CEF não atuam em idênticos objetivos aos bancos privados. A participação acionária estatal não pode ser equiparada a um ativo destinado simplesmente a produzir lucros. "A exploração da atividade econômica é apenas um meio para o Estado alcançar finalidades públicas, o que atribui à empresa pública e à sociedade de economia mista uma função tipicamente instrumental" (PINTO JUNIOR, 2010, p. 247).

Há que se reconhecer que as duas empresas estatais aqui indicadas obtiveram lucros de considerável quantia em 2015, de modo que "o BNDES é lucrativo e que os gestores obtêm margens líquidas de juros positiva principalmente por contarem com o custo de capital extremamente baixo em razão de grande parte de seus lucros ser oriunda de investimentos. Suas margens, contudo, dependem principalmente de capital subsidiado, fornecido pelo governo" (MUSACCHIO, LAZZARINI, 2014,p. 299).

Todavia, o número positivo isolado não deve ser festejado sem considerar o seu contexto. A sociedade não pode se contentar com valores isolados e desprovidos de uma análise sistemática. A questão que se faz é: por que o lucro não foi maior, mesmo utilizando-se de crédito subsidiado e políticas públicas que destinam a esses bancos a gestão de fundos públicos?

A primeira resposta passível de justificação é que a atuação de ambos não seguem, em um primeiro momento, a ótica especulativa do mercado. Alguns investimentos de longo prazo podem ser realizados desde que o retorno social seja concreto e o rendimento abaixo das taxas médias de mercado. $\mathrm{O}$ atendimento a objetivos sociais exige a concessão de créditos com juros menores, a abertura de agências em lugares remotos, o financiamento de investimentos de pessoas de baixa renda, a concessão de microcréditos, entre outros. Há críticas a essa ideia, porquanto "o mercado de crédito é acometido por diversas falhas. Há muito a ser feito para melhorar o funcionamento desse mercado no Brasil. Uma coisa, contudo, é certa: os empréstimos subsidiados do BNDES não melhoram o mercado como um todo, apenas tornam o crédito mais barato para alguns à custa de outros" (GUIMARÃES, 2015, p. 57). Ainda assim, é reconhecido como um modelo para propiciar serviços básicos à população de baixa renda.

A segunda verificação está no fato que essas entidades devem pautar-se pelos princípios da Administração Pública, sendo a ela inerentes os procedimentos de contratação por processo seletivo de pessoas (concurso), contratação de serviços e obras por licitação (Lei n. 8.666/1993), observância da Lei de Transparência n. 12.527/2011, entre outras burocracias que mitigam a observância, unicamente, do princípio da eficiência. Somente com gasto de pessoal, em 2015, a CEF desembolsou R \$ 19,75 bilhões para 97.458 colaboradores, mantidos em 3.404 agências em todo o Brasil para atendimento a 82.923 clientes pessoas físicas ou jurídicas, de acordo com o Balanço de $2015^{14}$. São procedimentos que oneram as atividades diárias de cada um dos envolvidos.

E por último é que se chega a questão tributária. Assim como qualquer outro banco, o BNDES e a CEF arcam com uma pesada carga tributária, com valores que afetam a disponibilização de caixa e prejudicam o investimento, quiçá maior, em programas sociais. E tal constatação é de todo modo paradoxal: de um lado impõe-se a observância de objetivos sociais, afetando a competitividade, enquanto de outro considera as atividades, para fins de tributação, idênticas a qualquer outro banco.

14 Disponível em: http://www20.caixa.gov.br/Lists/PresentationGallery/Press\%20Release\%204T15\%20\%20\%20Versao\%2007_03_2016_19h16.pdf

Revista de Direito Brasileira | São Paulo, SP | v. 15 | n. 6 | p. 295 - 310 | set./dez. 2016 
Em 2015 a CEF arcou com o pagamento de R\$ 1,14 bilhão em tributos ${ }^{15}$, enquanto que o BNDES, no ano de 2014, declara que pagou a quantia de R $\$ 3,22$ bilhões em tributos ${ }^{16}$. Tal quantia não é diferente daquela realizada pelos demais bancos atuantes no setor, porém, os demais bancos não possuem como ônus de sua existência realizar objetivos sociais.

$\mathrm{O}$ que se verifica, pelo arcabouço institucional que desvela as empresas estatais, especialmente pelo viés tributário, é que a CEF e o BNDES deixam de conferir maiores lucros do que poderiam e, nesse sentido, é o Estado brasileiro que deixa de consolidar instituições de maior porte financeiro. Basta lembrar que, por definição, uma empresa pública é constituída com 100\% do capital público. O capital público é da sociedade e, com tais abreviações, é a própria sociedade que deixa de ganhar nesse paradoxo insofismável.

Nesse sentido, Geraldo Ataliba (2004, p.36) enuncia que "alguns princípios constitucionais foram tradicionalmente postos pelos sucessivos legisladores constituintes como fundamentais a todo o sistema e, por isso, em posição de eminência relativamente a outros. No Brasil, os princípios mais importantes são os da federação e da república". Assim sendo, se a o pacto federativo é a pedra fundamental de nossa República, como então justificar a incidência tributária sobre as empresas públicas e sociedades de economia mista que atuam de forma a perfazer a justiça redistributiva?

Também aqui o Brasil não delineia uma escolha clara de seus objetivos institucionais, prejudicando o desenvolvimento de instrumentos ainda mais eficazes de desenvolvimento econômico.

\section{CONSIDERAÇÕES FINAIS}

Alinhar estratégias estatais com todas as demais áreas do direito e economia traduz-se em planejamento. Se o objetivo é promover instituições e fortalecer o papel de determinado agente no mercado para uma finalidade social, não se pode pretender que esse mesmo agente atue em livre competição com os demais concorrentes. De igual forma, se é constituída uma entidade para atuar como agente de mercado econômico, visando corrigir apenas falhas de mercado, não se pode pretender que ele também perfaça programas sociais.

Por uma questão de produtividade, torna-se incompatível pretender que o mesmo agente traduza uma lógica da eficiência em segmentos naturalmente não competitivos, como o desenvolvimento de projetos sociais.

Porém, com relação a CEF e o BNDES é exatamente o que acontece no Brasil. Ambas são entidades que atuam na redução da desigualdade de renda e em programas sociais, porém, com o fardo de atuarem diretamente no mercado da livre iniciativa. E, por isso, nenhum benefício possuem, especialmente no âmbito tributário.

Cria-se assim uma desvantagem competitiva que macula a possibilidade de lucros maiores serem obtidos. O saldo positivo no final do ano não pode significar, por si só, o sucesso dessas instituições. É preciso que a sociedade fique atenta para aquilo que ela vem deixando de ganhar nesse paradoxo que reduz produtividade das empresas estatais ao mesmo tempo em que as colocam em igual cenário de competição frente à iniciativa privada.

Nesse jogo de instituições, quem sai perdendo é a sociedade, o povo, titular soberano do Estado, acionista único e majoritário dos recursos empregados pelas empresas estatais. Essa pode

15 Conforme Demonstrações Contábeis Consolidadas IFRS - Anual 2015. Disponível em: http://www.caixa.gov.br/Downloads/DC_IFRS_Dez15_final.pdf

16 Conforme Demonstrações financeiras consolidadas em IFRS em 31 de dezembro de 2014. Disponível em http://www.bndes.gov.br/SiteBNDES/export/sites/default/bndes_pt/Galerias/Arquivos/empresa/download/IFRS_201 4.pdf

Revista de Direito Brasileira | São Paulo, SP | v. 15 | n. 6 | p. 295 - 310 | set./dez. 2016 
ser a origem da fragilidade e descrédito das instituições que deveriam promovem o desenvolvimento do país.

A esperança é que pelo viés do planejamento, todas as arrestas sejam adequadas a um único modelo, sem gambiarras. O sucesso depende da medida em que as instituições conseguem oferecer possibilidades de solução para os problemas sociais sem que o desenvolvimento enfrente grandes obstáculos.

\section{REFERÊNCIAS}

AMARO, Luciano. Direito Tributário Brasileiro. 20 ed. São Paulo: Saraiva, 2014;

ATALIBA, Geraldo. República e Constituição. 2 ed. São Paulo: Malheiros, 2004;

ÁVILA, Humberto. Sistema constitucional tributário: de acordo com a emenda constitucional $n$. 42, de 19.12.03. São Paulo: Saraiva, 2004;

BNDES. Sítio eletrônico institucional. Disponível em: <http://www.bndes.gov.br/SiteBNDES/bndes/bndes_pt/Institucional/O_BNDES/Fontes_de_Recu rsos/> Acesso em: 20 abr. 2016;

Boletim de Desempenho Setorial. Disponível em: <http://www.bndes.gov.br/SiteBNDES/export/sites/default/bndes_pt/Galerias/Arquivos/empresa/ estatisticas/Bol_Desempenho_e_Setorial.pdf> Acesso em: 20 abr. 2016;

\section{Disponível} . Lucro do BNDES até setembro foi de R\$ 6,6 bilhões. Publicado em 13/11/2015. http://www.bndes.gov.br/SiteBNDES/bndes/bndes_pt/Institucional/Sala_de_Imprensa/Noticias/2 015/Institucional/20151113_lucro.html> Acesso em: 20 abr. 2016;

Disponível . Demonstrações financeiras consolidadas em IFRS em 31 de dezembro de 2014. <http://www.bndes.gov.br/SiteBNDES/export/sites/default/bndes_pt/Galerias/Arquivos/empresa/ download/IFRS_2014.pdf> Acesso em: 20 abr. 2016;

BRASIL. Constituição (1988). Constituição da República Federativa do Brasil. Brasília/DF: Senado, 1998;

Empresas estatais. Ministério do Planejamento. Disponível em: http://www.planejamento.gov.br/assuntos/empresas-estatais/empresas-estatais-federais> Acesso em: 20 abr. 2016;

. Lei n. 5.662, de 21 de junho de 1971. Brasília/DF: Senado, 1971;

. Decreto-lei no 759, de 12 de agosto de 1969. Brasília/DF: Senado, 1969;

. Decreto-lei no 1.940, de 25 de maio de 1982. Brasília/DF: Senado, 1982;

BUFFON, Marciano, MATOS, Mateus Bassani. A tributação no século XXI: uma abordagem hermeneuticamente crítica. Porto Alegre: Do Advogado, 2015; 
Caixa Econômica Federal. Sítio eletrônico. Disponível em: <http://www.caixa.gov.br/sobre-acaixa/apresentacao/Paginas/default.aspx> Acesso em: 20 abr. 2016;

$$
\text { Balanço Social 2015. Disponível em: }
$$

<http://www20.caixa.gov.br/Lists/PresentationGallery/Press\%20Release\%204T15\%20\%20-

\%20Versao\%2007_03_2016_19h16.pdf> Acesso em: 20 abr. 2016;

. Demonstrações Contábeis Consolidadas IFRS - Anual 2015. Disponível em: http://www.caixa.gov.br/Downloads/DC_IFRS_Dez15_final.pdf>. Acesso em: 20 abr. 2016;

Caixa anuncia lucro de $R \$ 7,2$ bilhões e medidas para crédito imobiliário. Portal G1. Publicado em 08/03/2016. Disponível em: <http://g1.globo.com/economia/negocios/noticia/2016/03/lucroda-caixa-economica-sobe-para-r-72-bilhoes-em-2015.html> Acesso em: 20 abr. 2016;

CARRAZZA, Roque Antonio. Imunidade tributária das empresas estatais delegatárias de serviços públicos. São Paulo: Malheiros, 2004;

FEDERAÇÃO DOS BANCÁRIOS DO PARANÁ. Lucros dos bancos em 2015. Disponível em: <http://www.feebpr.org.br/lucroban.htm> Acesso em: 20 abr. 2016;

FIANI, Ronaldo. Cooperação e conflito. Instituições e desenvolvimento econômico. Rio de Janeiro: Elsevier, 2011;

GRAU, Eros Roberto. A Ordem Econômica na Constituição de 1988. 13. Ed. São Paulo: Malheiros, 2008;

. Lucratividade e função social nas empresas sob o controle do Estado. Revista de Direito Mercantil, Industrial, Econômico e Financeiro. São Paulo, n. 52, pp. 35-59, jul/set 1984;

GUIMARÃES, Bernardo. A riqueza da nação no século XXI. São Paulo: Bei Comunicação, 2015;

JARDIM, Eduardo Marcial Ferreira. Finanças públicas e tributação ao lume dos direitos e garantias. São Paulo: Noeses, 2015;

MAZZUCATO, Mariana. O Estado empreendedor: desmascarando o mito do setor público vs. setor privado. Trad. Elvira Serapicos; São Paulo: Penguin, 2014;

MELLO, Celso Antonio Bandeira. Sociedades mistas, empresas públicas e regime de direito público. Revista Eletrônica de Direito Administrativo Econômico, n. 10, maio/jun./jul. 2007.

MUSACCHIO, Aldo, LAZZARINI, Sérgio. Reinventando o capitalismo de estado: o leviatã nos negócios: Brasil e outros países. Trad. Afonso Celso da Cunha Serra. São Paulo: Penguin, 2014;

PINTO JUNIOR, Mario Engler. Empresa Estatal. São Paulo: Altas, 2010;

SALOMÃO FILHO, Calixto. Direito Concorrencial. São Paulo: Malheiros, 2013; 
Regulação e Desenvolvimento. São Paulo: Malheiros, 2002;

TORRES, Ricardo Lobo. Curso de Direito Financeiro e Tributário. 16 ed. Rio de Janeiro: Renovar, 2009;

WURSTER,Tani Maria. Imunidade recíproca em face das empresas públicas e sociedades de economia mista - critérios de incidência. Revista de Doutrina do TRF4. Publicado em 30.08.2013. http://revistadoutrina.trf4.jus.br/index.htm?http://revistadoutrina.trf4.jus.br/artigos/edicao055/Tan i_Wurster.html. 